\title{
MINI COFFEE GRINDER: UM PROJETO DE FOOD DESIGN LIGADO AO CONSUMO DO CAFÉ COM ÊNFASE NO SLOW MOVEMENT E NA EXPERIÊNCIA DO USUÁRIO DIANTE DO PRODUTO
}

\author{
Cheyenne Azevedo Barros \\ Universidade Federal de Juiz de Fora \\ chayazevedo91@gmail.com \\ Ivan Mota Santos \\ Universidade Federal de Juiz de Fora \\ santos.ivan@gmail.com
}

\begin{abstract}
Resumo: O presente artigo traz o processo de construção e os resultados de um projeto de conclusão de curso realizado na área de design de produto. Este projeto tem como foco o processo de preparo do café e sua relação com o slow movement - movimento que apoia a prática de modos de fazer algo de uma forma melhor e mais devagar. O crescente consumo da bebida, com novas e diversas formas de preparo, é visto como uma oportunidade para produzir um objeto que interfira neste processo. A etapa selecionada foi a moagem e, portanto, é proposto o desenvolvimento de um moedor (grinder) manual. Este grinder compõe um kit, também, constituído por grãos de café divididos em dois blends, sendo possível o consumo individual de cada um ou uma combinação entre ambos. Deste modo, o projeto visa a entrega deste kit com o objetivo de despertar o desejo do consumidor e estimulá-lo quanto ao preparo do café como um ritual, uma experiência sensorial repleta de detalhes importantes para a obtenção de um bom resultado.
\end{abstract}

Palavras-chave: Food design, slow movement, design de produto, café, grinder.

\begin{abstract}
This present article shows the manufacturing process and the final results of an end of course project developed on the Product Design area. This project has as its main approach the coffee making process and its relation with the "Slow movement" - A movement that stands for adopting a life style of making some things slower and in a better way. The consumption increase of the beverage, with many new brewing techniques is seen as an opportunity for the development of an object that interferes in this process. For that purpose the grinding moment was chosen, and therefore, the development of a manual coffee grinder. This grinder will be part of a kit, which will also be constituted by coffee beans divided into two blends, making possible an individual consume or a combination between both. By this way, this project aims, by delivering the kit, to arouse the
\end{abstract}


consumer's desire and encourage the coffee brewing process as a ritual, a sensitive experience full of small details, essential for achieving a good result.

Keywords: Food design, slow movement, product design, coffee, grinder.

\section{INTRODUÇÃO}

Atualmente, existe uma parcela de consumidores com olhares voltados aos produtos que possibilitam experiências sensoriais, tais como aromas e sabores que os remetam a um momento vivido. Concomitantemente, existem consumidores que têm dedicado parte do seu tempo à percepção dos detalhes e à valorização das etapas de um processo. A este movimento dá-se o nome de slow movement ${ }^{1}$.

Transportando este cenário ao consumo do café, pode-se perceber uma relação entre a dedicação a cada etapa do processo de preparo da bebida e a ascensão deste movimento cujos adeptos investem no tempo gasto com cada atividade desenvolvida. Somado a este fato está o crescente consumo da bebida mundialmente, inclusive no Brasil, que detém a primeira posição no ranking dos países produtores e exportadores de café de acordo com a Organização Internacional do Café (OIC) e a segunda posição como país consumidor do grão.

O café está relacionado aos aspectos culturais de cada povo e é consumido por diversas classes sociais e regiões do globo. No Brasil, a bebida tem deixado de ser consumida apenas pela manhã, através do preparo de coar, para ganhar um novo espaço nas casas e nas cafeterias especializadas na bebida. O café expresso tem ganhado cada vez mais destaque entre os principais tipos de cafés consumidos, assim como o cappuccino, o café extraído na prensa francesa, os blends vendidos para cafeteiras específicas como as máquinas Nespresso etc.

Neste projeto, foi enfatizado o processo de preparo da bebida como um ritual, no qual o consumidor tem papel fundamental para que o café seja extraído. $O$ consumo do café é estimulado entre os que já o apreciam, principalmente, o público jovem. Para despertar o interesse dos consumidores, foi desenvolvido um produto que visa tornar-se um objeto de desejo e que faça parte de uma das etapas do preparo do café: a moagem do grão.

A ideia principal é difundir o slow movement entre os jovens apreciadores de café através do desenvolvimento de um grinder manual que destaque a cultura e os processos de fabricação encontrados em Minas Gerais. Este produto foi desenvolvido para a marca Little Joy que, também, ressalta o valor dos momentos e dos pequenos prazeres.

Baseado nas metodologias de Dijon de Moraes (Metaprojeto) e Vijay Kumar (101 Design Methods), foram analisados diversos cenários que envolvem o públicoalvo deste projeto. Deste modo, foi possível conhecer o contexto ao qual a proposta está inserida e projetar algo coerente com o que foi definido. Estes cenários foram delimitados e estão resumidos nas páginas seguintes.

\footnotetext{
${ }^{1}$ Disponível na internet por http em: <http://www.slowmovement.com/>. Acesso em: 03 fev. 2016.
} 


\section{DESENVOLVIMENTO}

Grinders ou moedores são os objetos utilizados para a moagem do café em grãos. Este café é triturado e transformado no pó que conhecemos para o consumo.

Os grinders são compostos por alguns sistemas específicos de moagem, cada qual com as suas vantagens, desvantagens e indicações para determinados processos de extração. Entre os principais então o moinho em lâmina, o reto ou plano, o cônico e o moinho cilíndrico.

Os moedores podem ser classificados, também, como automáticos ou manuais e, em muitos casos, permitem a regulagem da granulometria, ou seja, do diâmetro dos grãos moídos de café.

Uma vez que o produto visa enfatizar o processo de preparo do café como um ritual, o grinder proposto possui um sistema manual de moagem, baseado em um sistema cônico. Este sistema foi selecionado por apresentar-se como o mais satisfatório - após alguns testes realizados com moedores domésticos - com relação à uniformidade de moagem e à preservação das propriedades do grão.

Segundo Arruda et al (2009), os consumidores do café associam o consumo da bebida a um hábito aliado ao prazer, à família, às amizades e ao trabalho, sendo a motivação de consumo pautada no significado social que o café assume, seja no círculo familiar, de trabalho ou entre amigos. Assim, aliar o consumo de café a uma experiência agradável constitui um caminho interessante para reforçar o consumo da bebida entre os jovens brasileiros. $E$, além da experiência, uma crescente parcela destes consumidores tem exigido, cada vez mais, a qualidade da bebida e o cuidado com o seu preparo.

[...] os esforços do setor cafeeiro em melhoria da qualidade do café produzido, maior percepção e exigências dos consumidores por cafés de qualidade, investimentos em marketing junto aos consumidores e profissionais da área médica desmistificando o conceito de que café faz mal à saúde e a consolidação e amadurecimento dos segmentos das cafeterias (MOREIRA, 2007 apud ARRUDA et al, 2009, p. 755 e 756).

Através de uma demanda crescente relacionada ao café, somada à busca pela experiência de consumo focada nos jovens e na cultura mineira, o conceito deste projeto gira em torno do desenvolvimento de um produto de uso doméstico que se torne objeto de desejo para o consumidor através do seu design e da experiência proporcionada pelo seu uso.

\subsection{Metodologia}

Para o desenvolvimento deste projeto foram adotadas duas metodologias: Metaprojeto, de Dijon de Moraes e 101 Design Methods, de Vijay Kumar.

De acordo com o Metaprojeto, foram confeccionados painéis imagéticos para que os cenários de usuário, sociocultural, benchmarking e materiais e processos fossem estruturados, conferindo o contexto geral ao qual o projeto seria inserido. Considerando que a sociedade e os usuários estão em constante mudança, esta metodologia sugere o estudo dinâmico dos cenários acima citados. Desta forma, novas análises e informações podem ser acrescidas e alteradas durante o desenvolvimento do projeto.

O livro 101 Design Methods propõe uma série de métodos já estudados para o desenvolvimento de projetos de design. Com base nesta organização de métodos, foi 
possível seguir o escopo básico sugerido, pautado na análise do contexto, coleta de informações para entender os cenários selecionados e, assim, o descarte daqueles aos quais o projeto não se destina. Deste modo, foi possível entender o mercado, as linguagens e o estilo de vida do usuário. Após estas fases de análise e entendimento e já com o usuário definido, esta metodologia propôs a criação de conceitos e alternativas voltadas aos mesmos. E, para estas possibilidades, foram feitas análises dos pontos positivos e negativos, eliminando algumas e tornando factíveis outras soluções até chegar ao produto final.

Em suma, o produto finalizado deve atender às metas e objetivos estipulados incialmente. Ou seja, a solução escolhida traduz os dados descritos na pesquisa apresentada, fazendo com que o produto supra as necessidades encontradas de acordo com o cenário definido.

\subsection{Usuário e contexto sociocultural}

A personalização dos produtos bem como a participação no processo de produção dos mesmos têm despertado a atenção de muitos perfis consumidores atualmente. São pessoas que buscam mais que um produto, mas uma ligação emocional com ele, seja por meio de um sentimento despertado ou por uma nova experiência vivida ao relacionar-se com o artefato de uma forma única.

Nos dias atuais, de acordo com Bressani (2015), o mercado voltado ao café é crescente. No Brasil, entre 2005 e 2006 o consumo de espresso aumentou em 63\% e, nos dias atuais, o café moído representa $76 \%$ do mercado consumidor. Além disso, em 2007, houve o crescimento em $42 \%$ de consumo de café fora de casa. Esses dados revelam a boa perspectiva para o investimento neste contexto, já que as pessoas têm, cada vez mais, buscado qualidade nos cafés e locais agradáveis para apreciá-los. Este crescente consumo também é visto entre os jovens que são atraídos pelos conceitos e inovações oriundos do universo do café.

Ainda que usuários de diferentes perfis possam consumir os produtos propostos neste projeto, haverá um foco maior nos jovens brasileiros entre 20 e 30 anos, classificados como um grupo consumidor da bebida ou produtos relacionados a mesma. Serão priorizados os perfis de usuários que valorizam o bem-estar e buscam um estilo de vida mais saudável; que recebem e filtram um grande número de informações. Este público preza pela criatividade e pelas inovações, além de praticar conceitos de sustentabilidade. Valorizam detalhes e a cultura associada às diversas práticas, por exemplo, relacionadas à gastronomia, aos esportes etc. Por este motivo, o projeto foca em um sistema mais artesanal que automático, evidenciando o processo de moagem como uma preparação delicada, em forma de ritual, para que ocorra uma posterior extração do café.

O projeto busca retomar práticas do passado, que valorizavam o próprio fazer, sem perder de vista o contexto presente ao qual estamos inseridos. Esta escolha será fundamentada no slow movement ${ }^{2}$, que consiste em um movimento pautado em uma maneira mais cuidadosa de fazer algo, valorizando o tempo e o momento de cada etapa do processo. O movimento visa "desacelerar" e é aplicado à diversas atividades cotidianas como comer, trabalhar, estudar, entre outras. O princípio sugere que seja

\footnotetext{
2 Disponível na internet por http em: <http://www.slowfoodbrasil.com/slowfood/o-movimento>. Acesso em: 03 fev. 2016.
} 
dada maior atenção a essas tarefas, aumentando a qualidade de cada uma delas e proporcionando bem-estar àqueles que o praticam. Faz parte deste movimento, também, a valorização da cultura local, com produções de qualidade que respeitem o ambiente e o consumidor. Ele entende que o usuário deve conhecer os processos em vez de adquirir produtos padronizados mundialmente. Em especial, de acordo com a vertente do slow movement dedicada à alimentação - o slow food - é defendido o uso de produtos artesanais, e é baseado nessas ideias que o projeto desenvolvido busca propiciar uma experiência ao usuário ligada ao ritual do preparo do café.

Assim como o próprio nome da marca ao qual o produto pertence - Little Joy, em português, "pequeno prazer" - os usuários são aqueles que prezam pequenos prazeres, momentos, detalhes. O modo "faça você mesmo", as possibilidades de fazer parte do processo do produto e não apenas comprá-lo pronto, as vivências e o conhecimento adquirido, são algumas questões que aproximam o usuário da proposta deste projeto.

O moedor foi pensado para tornar-se um objeto que desperte o desejo do consumidor. Já os blends permitem o desenvolvimento de coleções e edições especiais focados em perfis diferentes: aos que se preocupam com o corpo e praticam atividades físicas, aos que possuem uma rotina estressante de trabalho e precisam de energia ou um momento de relaxamento, aos que gostam de dormir mais cedo ou mais tarde. Ou seja, cada blend poderá ser pensado para um perfil, com um conceito específico.

\subsection{Benchmarking}

Para o benchmarking foram selecionados alguns tópicos, de acordo com o vídeo "What is Branding Anyway?"3. Este vídeo traz o conceito de branding baseado em cinco tópicos principais. Estes tópicos indicam o que uma marca deve ter para ser bem-sucedida diante do mercado. O que a marca representa, seu storytelling (história contada ao cliente que, de alguma forma, o "prende" a esta marca através de uma ligação emocional com a mesma), o design adotado, seu preço e o relacionamento com o cliente são componentes que constituem a cultura da marca, seu valor percebido diante dos consumidores.

Nesta sessão, foram analisadas as grandes redes como Starbucks, Nespresso, Lavazza, entre outras, que não concorrem diretamente com o projeto desenvolvido, mas vale a pena serem analisadas com relação ao que representam e como se relacionam com o cliente, além de suas características no que diz respeito ao design adotado, à apresentação do produto, entre outros. Além destas redes, foram estudadas, também, concorrentes e similares ao projeto, algumas focadas na produção de cafés e novos blends, outras voltadas à fabricação de grinders de café e, outras ainda, direcionadas à análise de seus locais físicos (cafeterias) e/ou virtuais para a venda dos seus produtos.

É possível perceber a existência de um mercado em crescimento que envolve cafeterias, serviços de entrega de diferentes cafés (clubes), grinders etc.

As cafeterias buscam o conforto e a fidelização do cliente. Têm como objetivo servir cafés e bebidas baseadas no grão com inovação, qualidade, tradição, dentre outras características. São exemplos: Santo Grão, The Woods Coffee, Pedra Bonita

\footnotetext{
${ }^{3}$ Disponível na internet por http em: <https://vimeo.com/13229280 >. Acesso em: 15 dez. 2015.
} 
Café. Em contrapartida, existem ainda aqueles locais que vão de encontro à proposta do Little Joy, porém mereceram destaque por conter um grande número de consumidores de café. São locais ligados ao consumo rápido, ao público que busca agilidade e instantaneidade no consumo, como a rede Starbucks.

No que diz respeito aos serviços ligados ao café, os clubes dedicados ao grão estão em evidência atualmente. Ressaltando a exclusividade dos assinantes são, em geral, sites cujos usuários recebem, periodicamente, novos cafés, selecionados com suas especificações e alguns artigos relacionados aos mesmos, que variam de clube para clube. Fazem parte desta categoria o Moka Clube, o Clube Café e o Coffeery, por exemplo.

Além das referências acima citadas, também foram analisados os grinders já existentes. Há diversos moedores, entre automáticos e manuais, com moinhos de lâminas, cônicos ou retos, aspectos estéticos diversos. Eles estão ilustrados a seguir.



Figura 1 - Exemplos de grinders manuais existentes no mercado atualmente. Fonte: Imagens retiradas do Google ${ }^{4}$.

A partir destas observações, alguns caminhos foram definidos como essenciais: o uso de peças internas fabricadas com um material que permita maior resistência e fácil limpeza do grinder, manivela lateral que confere maior conforto ao girá-la para moer o grão, utilização de um mesmo material em todo o moedor como um fator que torna os custos de fabricação menores e uso do moinho cônico, uma vez que este permite maior precisão na granulometria.

Deste modo, o estudo dos produtos existentes foi útil para definir os aspectos que seriam positivos e negativos ao projeto de acordo com as premissas do mesmo.

\footnotetext{
${ }^{4}$ Disponível na internet por http em: <www.google.com.br>. Acesso em 26 nov. 2015.
} 


\subsection{Materiais e processos de fabricação}

\subsubsection{Peças do grinder}

O produto, nomeado Mini Coffee Grinder Little Joy, é composto por um conjunto de dez peças que serão descritas a seguir.

Pega da tampa (1): permite a fixação das peças internas e da tampa à base da panela e acompanha o movimento giratório da haste. Tampa (2): encaixada na base da panela, a tampa permite o encaixe da manivela e da haste. É colocada após os grãos serem adicionados à panela e é fixada com a pega. Haste (3): peça central do moedor, sustenta a mós interna e uma engrenagem cônica que, ao entrar em contato com a engrenagem da manivela, permite o giro da mós interna para moer os grãos. Arruelas (4) e (6): fixam a mós interna após definida a sua granulometria. São colocadas acima e abaixo da peça. Mós interna (5): peça giratória que permite a moagem em conjunto com a mós externa (fixa). Através da sua distância com relação à mós externa a granulometria é definida. Engrenagem cônica (7): Entra em contato com a engrenagem fixa da haste para permitir, com o giro da manivela, que a mós interna seja movimentada moendo o café. Manivela (8): peça girada pelo usuário para moer os grãos. Bola da manivela (9): extremidade da manivela, permite que o usuário a segure para girar com mais conforto a manivela. Base da panela (10): peça que contém a mós externa em sua parede interna. Esta mós é fixa à base da panela e permite que os grãos sejam moídos entre ela (fixa) e a mós interna (móvel).

A seguir, está apresentado o render da vista explodida do Grinder desenvolvido com os componentes indicados pelos seus respectivos números citados no parágrafo anterior.

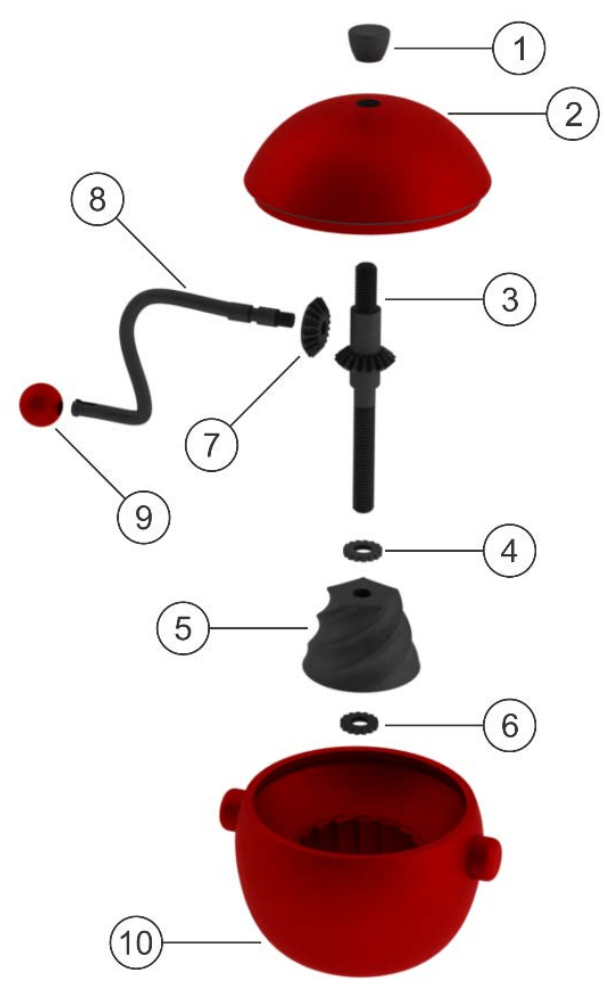

Figura 2 - Vista explodida do Mini Coffee Grinder Little Joy.

Fonte: Elaborado pelo autor, com base na pesquisa realizada. 


\subsubsection{Componentes internos e externos}

Internamente, as peças precisam ser resistentes e com fácil higienização. Sendo assim, o ferro e o processo de fundição são excelentes opções, pois oferecem a resistência necessária ao processo de moagem com custos menores quando comparados a outros processos de moldagem ou de usinagem, como aqueles que utilizam CNC. É importante ressaltar que para o processo de higienização do grinder não é necessário o uso de água e de produtos de limpeza. O objeto deve ser limpo, apenas, com o uso de um pincel. Este deverá ser utilizado até remover por completo os restos dos grãos moídos, deixando o produto pronto para a próxima moagem. No entanto, para a fabricação do modelo do grinder, foi utilizado o processo de impressão 3D em todos os componentes do objeto. Este processo foi disponibilizado na própria instituição de ensino, o que permitiu o acompanhamento durante o desenvolvimento do produto e a correção de possíveis erros de construção do objeto.

Externamente, as possibilidades são maiores. Cada material apresenta suas especificidades, pontos positivos e negativos. A madeira, por exemplo, pode acumular bactérias ao longo do tempo; os polímeros não possuem a mesma resistência dos metais etc. Os materiais podem ser utilizados isolados ou combinados entre si. Por questões relacionadas ao custo de fabricação, à durabilidade e à facilidade de limpeza, conforme dito anteriormente, os metais se destacaram. Somado a este fato, dentre os metais, o ferro foi escolhido por possibilitar a produção do grinder com um único material, tanto nas peças internas, quanto nas externas. Além do uso do processo de fundição, permitindo que, posteriormente, os grinders sejam esmaltados e disponibilizados em cores diversas. Este aspecto é importante para torná-lo um produto com aparência jovem, conforme definido no conceito do projeto. Desta forma, utilizar o ferro em todo o produto possibilita menores custos de produção e fabricação por um mesmo fornecedor. Outro ponto decisivo para a escolha do material foi a existência de polos de fundição de ferro em Minas Gerais, como a cidade de Claudio e o aspecto cultural encontrado no processo.



Figura 3 - Render do Mini Coffee Grinder Little Joy. Existem diversas possibilidades de cores para a produção dos moedores.

Fonte: Elaborado pelo autor, com base na pesquisa realizada.

\subsection{Mini Coffee Grinder Little Joy}

Durante a geração das ideias e das alternativas, a primeira dificuldade encontrada foi adaptar o produto à cultura mineira. Os primeiros sketches mostraram- 
se relacionados aos produtos europeus, com formas geométricas retas e ausência de cores. A forma final foi resolvida com base nas panelas de ferro fundido esmaltadas e nas moringas de barro produzidas em Minas Gerais, que remetem às fazendas mineiras, ao fogão a lenha e, por consequência, ao café com pão de queijo tradicional do estado. As peças deveriam ter encaixes perfeitos e formas harmônicas para garantir o funcionamento correto do produto.

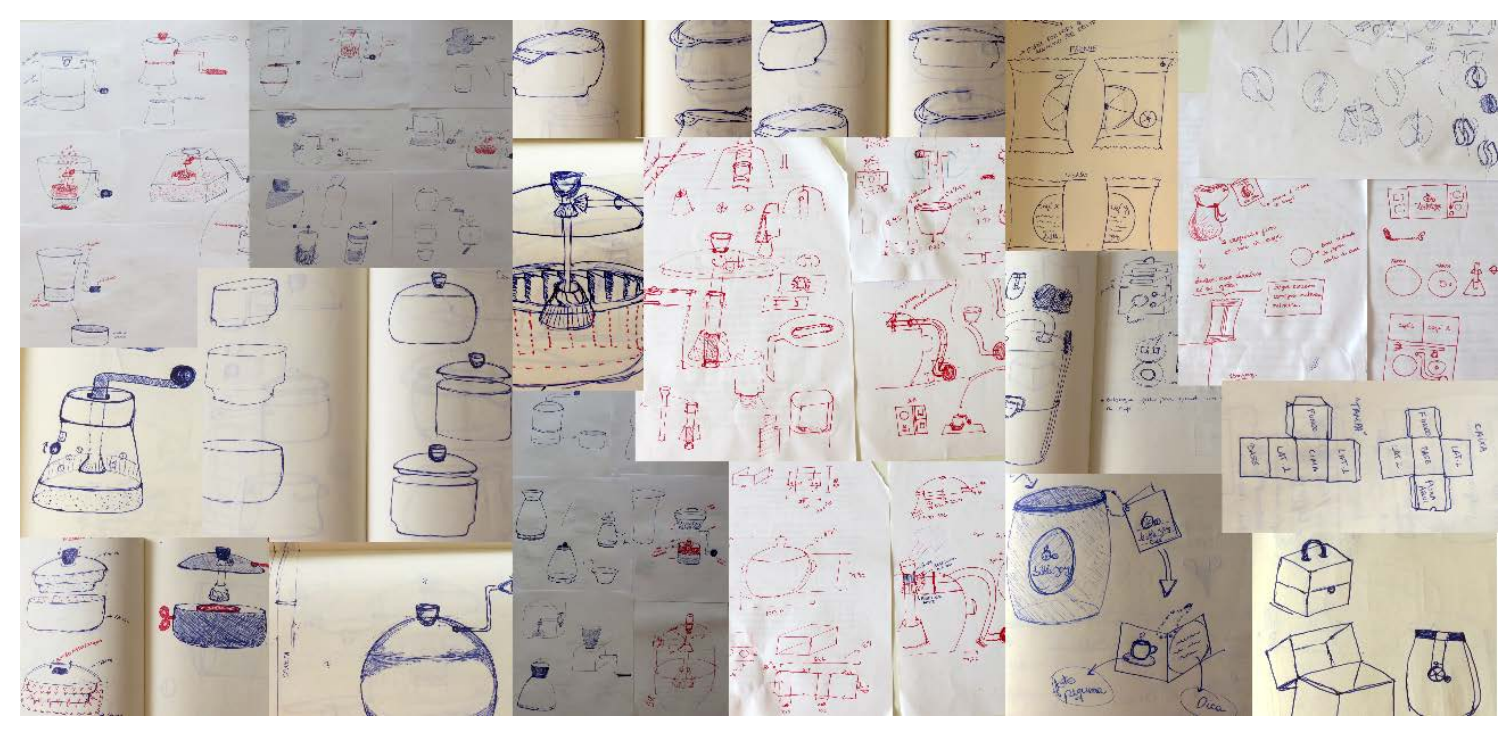

Figura 4 - Processo de geração de ideias e alternativas para o moedor e embalagens.

Fonte: Elaborado pelo autor, com base na pesquisa realizada.

Foi proposta uma releitura de um objeto tradicional - moedores antigos manuais - com uma visão moderna, ergonômica e factível voltada à cultura mineira e ao público jovem consumidor de cafés e frequentador de cafeterias. As pegas laterais visam remeter ainda mais a este contexto. A pega superior à tampa da panela, além do caráter estético que alude ainda mais à forma buscada no objeto final, permite que a mós interna seja fixa ao mesmo tempo em que possa girar para efetuar a moagem. A manivela - que permite seu uso por destros e canhotos - é posicionada lateralmente para atender a uma questão ergonômica. É possível que o usuário apoie o moedor na superfície escolhida, aplique uma leve força ao segurar a tampa com uma das mãos enquanto gira a manivela com a outra diferentemente dos moedores com manivelas superiores.

Para a fabricação do modelo de apresentação do Grinder, foi utilizado o processo de impressão 3D. O uso deste processo nesta etapa do desenvolvimento do projeto permitiu a verificação dos encaixes e do funcionamento do produto de uma forma praticamente instantânea, dada a velocidade da impressão, possibilitando a confirmação da usabilidade do produto. As imagens do modelo finalizado estão dispostas a seguir. 


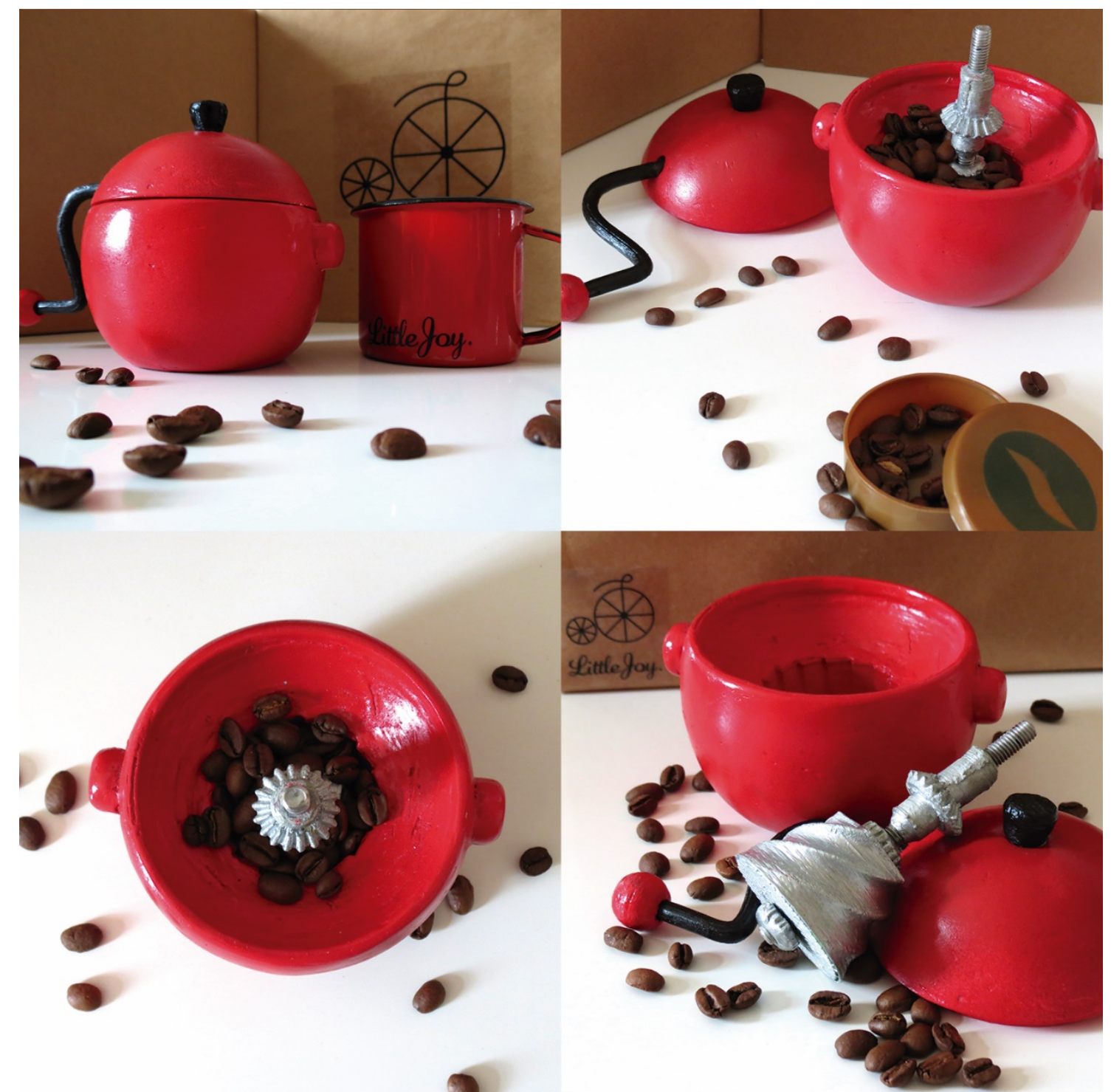

Figura 5 - Modelo produzido em impressão 3D do Mini Coffee Grinder Little Joy.

Fonte: Elaborado pelo autor, com base na pesquisa realizada.

O local de armazenamento do café deve protegê-lo de calor, umidade e luz excessiva. Em geral, esses recipientes devem ser opacos e, uma vez abertos, devem ser vedados enquanto não estão em uso. $O$ café em grãos possui maior durabilidade que o café em pó, enquanto o primeiro pode ser guardado, sem perda de propriedades, por um dia, o segundo mantém suas propriedades apenas por 15 minutos após aberto ou moído. Este fato se deve ao processo de oxidação que é iniciado logo após a moagem dos grãos, por isso o café deve ser comprado aos poucos e moído somente a quantidade necessária para a dosagem que será consumida (BRESSANI, 2015). Sendo assim, os blends e as embalagens também são produtos integrantes do kit Little Joy e foram desenvolvidos para a melhor conservação do grão.

As embalagens e elementos gráficos foram pensados de acordo com o grão de café e suas tonalidades. Foram desenvolvidos de modo que pudessem ser complementares - no caso da embalagem dos blends os dois grãos se completam nas ilustrações - e que pudessem aludir às grandes sacas de café utilizadas para comercialização do grão. 


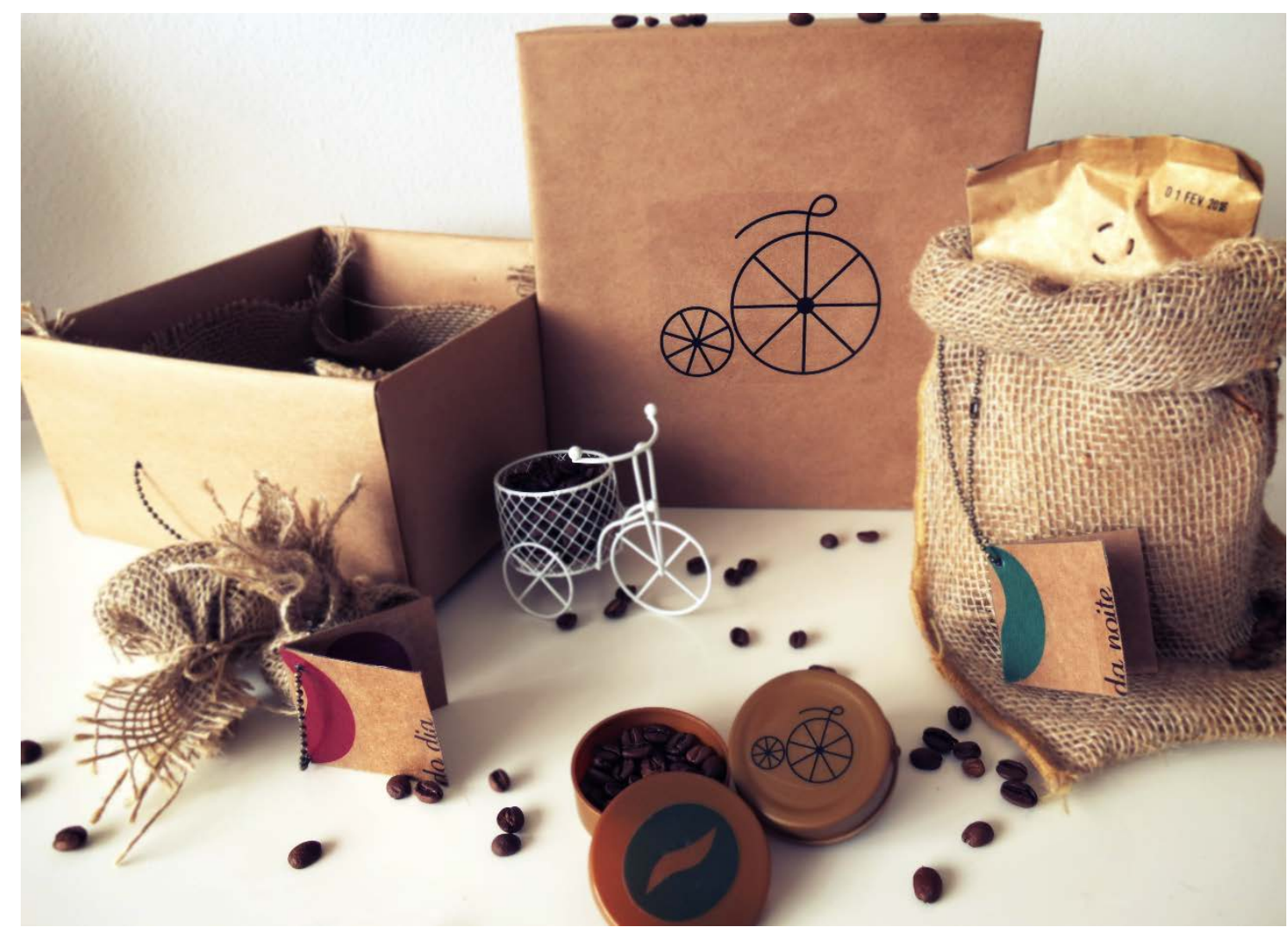

Figura 6 - Conjunto, finalizado, de embalagens, blends de café e identidade visual desenvolvidos para acompanhar o Grinder no kit proposto.

Fonte: Elaborado pelo autor, com base na pesquisa realizada.

Com um conceito direcionado ao slow movement, o grinder projetado tem como característica o funcionamento manual, que leva ao preparo de uma dose de café por vez como um ritual que demanda tempo, dedicação e atenção. Este conceito visa estimular o bem-estar, à criatividade e os pequenos prazeres.

Sendo assim, o Mini Coffee Grinder Little Joy pretende oferecer um café com qualidade ao seu público. Seja a qualidade da bebida, ao interferir no preparo do grão, seja o aumento na qualidade de vida do próprio consumidor.

\section{CONCLUSÃO}

A realização deste projeto foi pautada, incialmente, na divulgação da marca Little Joy e sua proposta direcionada ao café e às boas experiências que este pode proporcionar. Assim, a proposta do kit incluiu a tradução da marca em um produto.

Após a construção do modelo, possíveis melhorias poderão ser feitas para a fabricação de um protótipo do produto - alguns testes com materiais alternativos e pequenos ajustes de dimensões. Deste modo, o grinder será testado com pessoas mais próximas, como estratégia de receptividade do mercado e, posteriormente, comercializado em algumas cafeterias locais.

A produção inicial será em pequenos lotes, para averiguar a aceitação do público, além de ser dedicada a obtenção de lucros para os lotes seguintes.

Durante este período, também serão feitos investimentos em cursos que permitam a qualificação nas áreas relacionadas ao café - cursos de barista e drinks com café encontrados na escola paulista Coffee Lab, por exemplo. 
Em seguida, novos produtos serão pensados e desenvolvidos, além da criação de um website Little Joy para a comercialização direta dos mesmos e de perfis em redes sociais como estratégia de aproximação e relacionamento entre a marca e seu público-alvo.

Através deste processo, busca-se a construção e abertura da própria sede Little Joy, uma cafeteria com a venda dos próprios blends de café e produtos relacionados ao mesmo.

\section{REFERÊNCIAS}

ARRUDA, A. C. et al. Justificativas e motivações do consumo e não consumo de café. Ciência e Tecnologia de Alimentos, Campinas, v. 29, n. 4, p. 754763, out./nov./dez. 2009.

ASHBY, Michael; JOHNSON, Kara. Materiais e Design: Arte e ciência da seleção de materiais no design do produto. Rio de Janeiro: Elsevier, 2011.

BRESSANI, Edgard. Guia do Barista: Da origem do café ao espresso perfeito. São Paulo: Café Editora, 2015.

ESCOLA DE DESIGN, UEMG. Manual para elaboração e normalização de trabalhos acadêmicos e técnico-científicos da ED/UEMG. Belo Horizonte: Editora UEMG, 2015.

ESPRESSO. São Paulo: Café Editora, n. 47, mar./abr./mai. 2015.

KULA, Daniel; TERNAUX, Eloide. Materiologia: 0 guia criativo de materiais e tecnologias. São Paulo: Editora Senac, 2012.

KUMAR, Vijay. 101 Design Methods: A structured approach for driving innovation in your organization. Canadá: Wiley, 2015.

LIMA, Marco Antônio Magalhães. Materiais e Processos para Designers. Rio de Janeiro: Ciência Moderna, 2006.

MORAES, Dijon de. Metaprojeto: O design do design. São Paulo: Blucher, 2010.

MOREIRA, M. Mais um café por favor. Jornal do café. n. 157, p. 6-10, 2007. apud ARRUDA, A. C. et al. Justificativas e motivações do consumo e não consumo de café. Ciência e Tecnologia de Alimentos, Campinas, v. 29, n. 4, p. 754-763, out./nov./dez. 2009.

THOMPSON, Rob. Manufacturing processes for design professionals. Reino Unido: Thames \& Hudson, 2007. 